\title{
O PAPEL DO ERRO NO PROCESSO DE ENSINO E APRENDIZAGeM DE Ciências E Matemática: CONTRIBUTOS DA NEUROCIÊNCIA
}

\author{
THE ROLE OF ERROR IN THE TEACHING AND LEARNING PROCESS OF \\ SCIENCE AND MATHEMATICS: CONTRIBUTIONS FROM NEUROSCIENCE
}

DOI: 10.23926/RPD.2526-2149.2020.v5.n2.p1171-1190.id759

\author{
José Ademir \\ Damasceno Júnior \\ Mestre em Ensino de \\ Ciências e Matemática \\ (IFCE) \\ Professor da Secretaria da \\ Educação Básica do Ceará \\ (SEDUC) \\ jose.junior43@prof.ce.gov.br
}

\begin{abstract}
Resumo: Nesta pesquisa, realizou-se uma investigação sobre a compreensão do erro no processo de ensino e aprendizagem. Nesse sentido, levantou-se uma questão central: a partir das contribuições da Neurociência, qual o papel do erro no processo de ensino e aprendizagem de Ciências e Matemática? A pesquisa tomou por base autores da área, documentos oficiais nacionais, e resultados de pesquisas anteriores descritos em artigos, dissertações e teses, no período de 1983 a 2019. Os resultados indicam que através da compreensão do erro, sua gênese e desenvolvimento, especialmente à luz da Neurociência, será possível superá-lo, assim, favorecer a atuação do professor, permitindo que ele aborde os conceitos de Ciências e Matemática com estratégias mais adequadas. Todavia, a interlocução entre a Neurociência e a Educação não deve se limitar em obter o conhecimento dos mecanismos cerebrais para a sua aplicação, sem levar em consideração o contexto do sistema educacional.
\end{abstract}

Palavras-chave: Ciências e Matemática. Ensino. Aprendizagem. Neurociência. Erro.

\begin{abstract}
In this research, an investigation was carried out on the understanding of the error in the teaching and learning process. In this sense, a central question was raised: from the contributions of Neuroscience, what is the role of error in the teaching and learning process of Science and Mathematics? The research was based on authors in the field, national official documents, and results of previous research described in articles, dissertations and theses, from 1983 to 2019. The results indicate that through understanding the error, its genesis and development, especially at the In the light of Neuroscience, it will be possible to overcome it, thus favoring the performance of the teacher, allowing him to approach the concepts of Science and Mathematics with more appropriate strategies. However, the dialogue between Neuroscience and Education should not be limited to obtaining knowledge of the brain mechanisms for its application, without taking into account the context of the educational system.
\end{abstract}

Keywords: Sciences and Mathematics. Teaching. Learning. Neuroscience. Mistake. 


\section{INTRODUÇÃO}

Não obstante, encontramos depoimentos de inúmeros professores de escolas brasileiras que ainda tratam os erros apresentados pelos alunos no processo de aprendizagem como um fator essencialmente negativo. Entretanto, acredita-se que o erro deve ser compreendido como uma oportunidade de aprendizado (CHIQUETTO, 2011). Além disso, atualmente, verifica-se também que os erros cometidos pelos alunos em sala de aula, por exemplo, em resoluções de questões na aplicação de testes, são tratados apenas como fatores de punição e não discutidos/explorados por boa parte dos professores. Para muitos docentes, discutir sobre o erro não faz parte do processo de aprendizagem (SILVA, 2019).

No Brasil, historicamente, a percepção do erro somente como uma evidência do nãoaprendizado é bastante acentuada nas avaliações em larga escala, por exemplo, no Exame Nacional do Ensino Médio (ENEM), entre outras, além do fato de que as escolas, e o próprio sistema escolar, também são avaliadas nesse processo. Por outro lado, geralmente, ao aluno é negado a possibilidade de aprender com os erros, devendo quase que obrigatoriamente evitálos (CHIQUETO, 2011). Para uma melhor compreensão e uso pedagógico do erro, na perspectiva de uma aprendizagem mais significativa pelo aluno, urge a necessidade da mobilização de um processo dialético fundamentado em raízes epistemológicas e didáticas (BATISTA, 2018).

No tocante à Neurociência, Bartoszeck (2006) elucida que essa área do conhecimento realiza um criterioso estudo do sistema nervoso central e de sua complexidade. Segundo Vizzotto (2019), a Neurociência passou a ser considerada ciência formal somente no século XIX, valendo-se do estudo de estímulos cerebrais, através do qual se inferiu que as sinapses neurais podem sofrer mudanças. Nesse contexto, Relvas (2011) advoga que os cérebros têm, indistintamente, a possibilidade de se modificar, ou seja, este órgão tem a capacidade da passar por alterações em meio a novas aprendizagens.

De acordo com Vizzotto (2019), à luz dos fundamentos da Neurociência, a aprendizagem está envolvida com as bases químicas e físicas da função neural. Sendo, justamente, esta estrutura responsável pela transmissão e decodificação das informações recebidas nesse processo. Ademais, a Neurociência tem uma relevante função na compreensão da estrutura, organização e funcionamento do cérebro (VIZZOTTO, 2019).

Grossi, Lopes e Couto (2014) esclarecem que a Neurociência dialoga com diferentes áreas do conhecimento, entre tantas outras: a neurologia, a psicologia e a biologia. Acrescentam ainda que ela apresenta como tema central o estudo do sistema nervoso (SN), 
consequentemente, a interpretação do processo de aprendizagem. Por outro lado, em função da relevância das teorias e métodos pedagógicos para o ensino, a interface Neurociência e Pedagogia ocupa papel de destaque nesse contexto.

Segundo Guerra (2011), baseando-se nos fundamentos da Neurociência, o erro oportuniza momentos de reflexão, possibilitando aos indivíduos outras formas de resolver problemas, representando, assim, uma valiosa estratégia a fim de tornar o processo de aprendizagem mais eficiente. Nota-se, frequentemente, professores, de diferentes níveis, pedindo atenção aos seus alunos em sala de aula. Considera-se a atenção como uma função cognitiva, tendo exercido um papel fundamental na evolução da humanidade, especialmente através do processo seletivo capaz de realizar, focalizando no que interessa, nas informações imprescindíveis para a sua sobrevivência, em detrimento de outros estímulos menos importantes (STERNBERG, 2010; WILLINGHAM, 2011; SILVA 2019).

Sendo assim, no tocante à aprendizagem, a atenção representa um fator determinante, pois focaliza os estímulos necessários e despreza os contrários à absorção de informações (SILVA, 2019). Partindo desses pressupostos, sugere-se, então, uma questão central: quais os contributos da Neurociência sobre o papel do erro no processo de ensino e aprendizagem de Ciências e Matemática? Portanto, este trabalho teve como objetivo geral realizar um levantamento bibliográfico sobre os contributos da Neurociência sobre o papel do erro no processo de ensino e aprendizagem de Ciências e Matemática.

\section{REFERENCIAL TEÓRICO}

O erro pode se manifestar a partir de certas concepções espontâneas, reconstruídas ou alternativas, que, por meio de uma rede imbricada de representações cognitivas, passam a representar obstáculos à aquisição e ao domínio de novos conceitos (BROUSSEAU, 1983; ALMOULOUD, 2007). Inúmeros pesquisadores em didática da matemática acreditam que o erro do aluno, de acordo com o tratamento que é dado pelo professor, pode significar um dos fatores que mais influenciam na aprendizagem. Vale destacar que esse tratamento está ancorado na concepção de aprendizagem do professor (ALMOULOUD, 2010).

$\mathrm{Na}$ visão de Oliveira et al. (2012), Brousseau aponta diferentes origens para os obstáculos identificados na didática da matemática, a saber: epistemológicos, didáticos, psicológicos e ontogênicos. No que concerne aos obstáculos epistemológicos, estes se referem à construção do conhecimento no decorrer da História e da própria construção cognitiva do 
indivíduo. Por exemplo, o conceito de infinito, o zero e o conhecimento de função representam para os alunos obstáculos epistemológicos (OLIVEIRA et al., 2012).

Oliveira et al. (2012) revelam, alinhados com os conceitos de Brousseau, que os obstáculos didáticos surgem a partir da seleção feita pelo professor de suas estratégias de ensino. Desse modo, o conhecimento se torna questionável quanto a sua validade, ao mesmo tempo, se compartilhado de forma incompleta será configurado como obstáculos para a construção dos conceitos.

Os autores citam, como exemplo, que os alunos não têm consciência, em relação aos números decimais, da densidade dos números reais. Almouloud (2007) corrobora com esse pensamento ao afirmar que os alunos apresentam dificuldade em compreender a existência de infinitos números decimais entre dois quaisquer números. Nessa conjectura, tanto o projeto do sistema educativo quanto as estratégias de ensino adotadas pelo professor devem ser criteriosamente selecionados/construídos, com o intuito de que a construção do conhecimento a ser realizada não seja incompleta e questionável.

Para Almouloud (2007), os obstáculos surgem devido à necessidade de novos conhecimentos para resolver certos problemas, pois os conhecimentos prévios do indivíduo não são suficientes ou ineficazes para superarem os erros cometidos. Consoante Silva (2019, p. 57), "esses obstáculos são inevitáveis e inerentes com relação à transposição didática, apesar de que seu reconhecimento pode munir o professor rever a introdução escolhida para ensinar determinado conceito, visualizando assim a dificuldade vivida pelo discente".

[...] a Transposição Didática pressupõe a existência de um processo no qual "um conteúdo do saber tendo sido designado como saber sábio, sofre, a partir daí, um conjunto de transformações adaptativas que o levam a tomar lugar entre os objetos de ensino. O trabalho em tornar um objeto do saber sábio em objeto do saber ensinado é denominado Transposição didática.”. Ou melhor, a Transposição Didática analisa as transformações ocorridas no saber de referência (Saber Sábio) até se tornar um saber da sala de aula (Saber Ensinado) (SIQUEIRA; PIETROCOLA, 2006).

Astolfi e Develay (2002) alertam que, no processo de transposição didática, três elementos devem ser levados em consideração, a saber: práticas sociais de referência, níveis de formulação de um conceito e tramas conceituais. Portanto, de acordo com os autores, existe um conceito de epistemologia escolar que diverge da epistemologia dos saberes de referências. Sendo assim, Astolfi e Develay (2002) explicam que a epistemologia escolar resulta das transformações ocorridas pelo saber sábio que implicam, por consequência, no distanciamento dos conceitos originais apresentados pelos cientistas, elaborados pelo saber sábio. 
As práticas sociais de referências, em consonância com Astolfi e Develay (2002), criticam a ideia de Chevallard (um dos teóricos precursores do conceito de transposição didática) sobre o saber sábio. Chevallard não considerava as atividades de pesquisas, as culturais ou as domésticas como práticas sociais de referência, sendo que estas poderiam servir como referência por terem saberes contidos e eficientes para aprendizagem (ASTOLFI; DEVELAY, 2002).

Conforme Astolfi e Develay (2002), o segundo elemento são os níveis de formulação de um conceito, ou seja, são níveis de formulação ou exemplos que começam simples e depois, em consonância com o plano linguístico, psicogenético e epistemológico do indivíduo, tornamse complexos. É a construção de um conceito, partindo do mais elementar para o mais elaborado, este mais difícil de ser assimilado (JARDIM; CAMARGO; ZIMER, 2015).

Astolfi e Develay (2002) apontam as tramas conceituais como o terceiro elemento. Elas representam enunciados diferentes e evolutivos sobre um mesmo conceito, representando a construção do conhecimento pelos estudantes, de forma orientada, a fim de que os assuntos sejam assimilados com eficiência (JARDIM; CAMARGO; ZIMER, 2015). Nesse viés, de transição do conhecimento, notadamente no ensino de Ciências e Matemática, percebe-se facilmente na literatura científica, e nos estudantes brasileiros, o processo de erro relacionado ao conhecimento popular ou comum.

Sobre o conhecimento popular ou conhecimento comum, Damasceno Júnior e Romeu (2018) explicitam que suas concepções comprometem o ensino de Ciências e que, segundo o teórico Gaston Bachelard, são apontadas como obstáculos epistemológicos. Os obstáculos epistemológicos “constituem-se como fatores de resistência, conservação do pensamento, uma preferência pelas respostas prontas e não por questioná-las" (DAMASCENO JÚNIOR; ROMEU, 2018, p. 234). O conhecimento comum tem um caráter empiricamente unificado do real, um conhecimento imediato, por outro lado, o conhecimento científico representa um pensamento abstrato, reflexivo e racional (BACHELARD, 2006; DAMASCENO JÚNIOR; ROMEU, 2018).

Consoante Oliveira et al. (2012), os obstáculos psicológicos são revelados quando o conteúdo apresentado pelo professor entra em conflito com o contexto do aluno, vai de encontro a sua vida e desejos, como, por exemplo, o caso do zero, que nada representa para ele, e a lógica matemática que, frequentemente, divergente da lógica cotidiana. Já os obstáculos ontogênicos se configuram como as limitações neurofisiológicas do indivíduo conforme sua etapa de desenvolvimento. A linguagem formal matemática que, dependendo da idade do aluno, por 
exemplo, muitas vezes não é completamente compreendida, ocupando um nível acima da compreensão do aluno (OLIVEIRA et al., 2012).

Vizzotto (2019) explicita que a investigação da aprendizagem, enquanto objeto de estudo, teve início com a área da psicologia, por consequência, deu origem à psicologia do desenvolvimento ou psicologia da aprendizagem, vislumbrando entender as funções cognitivas. Por sua vez, Vizzotto (2019, p. 153) levanta a seguinte questão:

[...] há décadas são realizados estudos buscando entender esse contexto e ainda não existe um consenso entre os autores clássicos e pesquisadores contemporâneos sobre como a mente humana aprende e o quais são os mecanismos que o cérebro utiliza para esse acontecimento (VIZZOTTO, 2019, p. 153).

Nesse sentido, Vizzotto (2019) aponta que as teorias da aprendizagem utilizam em suas investigações métodos indiretos com vistas a apreciar a assimilação de conceitos ou condicionantes, buscando compreender as especificidades da aprendizagem. Vizzotto (2019, p. 154) afirma que "[...] acreditava-se que aprender dependia de fatores externos ao indivíduo e que o contato com o mundo, por meio dos sentidos, proporcionaria a integração necessária para 'adquirir' conhecimentos”. Ele ressalta também que essa concepção se apoiou em uma vertente, atualmente denominada natureza empirista/indutivista, fundamentada na teoria Behaviorista. Todavia, Vizzotto (2019, p. 154) adverte que:

\section{[...] essa compreensão era altamente questionável pois a confiança nos sentidos humanos poderia facilmente ludibriar a validade das medidas realizadas, pois são instrumentos passíveis de falhas. No outro extremo, acreditava-se que a aprendizagem ocorria devido à interação com o meio, através de raciocínios dedutivos. Essa linha, chamada de racionalista, teve como principais representantes Piaget e Vygotsky, com as visões cognitivistas e sociointeracionistas, respectivamente (VIZZOTTO, 2019, p. 154).}

Por outro lado, há autores que defendem que nem o extremo empirista nem o racionalista revelam totalmente os aspectos fundamentais para compreender a aprendizagem (VIZZOTTO, 2019). Vale frisar que essas duas vertentes precisam dialogar, com o intuito de esclarecer possíveis influências que contribuam para o fenômeno da aprendizagem (VIZZOTTO, 2019). Conforme Cosenza e Guerra (2011, p. 38), sob a ótica da Neurociência, o fenômeno da "aprendizagem" pode ser definido por:

[...] uma facilitação da passagem da informação ao longo das sinapses. Mecanismos bioquímicos entram em ação, fazendo com que os neurotransmissores sejam liberados em maior quantidade ou tenham uma ação mais eficiente na membrana pós-sináptica. Mesmo sem a formação de uma nova ligação, as já existentes passam a ser mais eficientes, ocorrendo o que já podemos chamar de aprendizagem [..] (COSENZA; GUERRA, 2011, p. 38). 
Ainda assim, para que a aprendizagem seja mais sólida “[...] novas ligações sinápticas serão construídas, sendo necessário, então, a formação de proteínas e de outras substâncias. Portanto, trata-se de um processo que só será completado depois de algum tempo" (COSENZA; GUERRA, 2011, p. 38).

[...] a aprendizagem se traduz pela formação e consolidação das ligações entre as células nervosas. É fruto de modificações químicas e estruturais do sistema nervoso de cada um, que exige energia e tempo para se manifestar. Professores podem facilitar o processo, mas, em última análise a aprendizagem é um fenômeno individual e privado e vai obedecer às circunstâncias históricas de cada um de nós (COSENZA; GUERRA, 2011, p. 38).

Idealizada por David Ausubel, a teoria da Aprendizagem Significativa se baseia na construção de um novo conhecimento através da interação não-arbitrária e não-literal com os conhecimentos prévios, também chamados de subsunçores, que servirão para ancorar os novos conhecimentos. Nesse contexto, o estudante precisa do conhecimento prévio dentro de sua estrutura cognitiva, com o propósito de estabelecer uma associação com o novo conhecimento, para dar-lhe significado, caso contrário não poderá desenvolver uma aprendizagem significativa (MOREIRA et al., 2008).

Com a finalidade de esclarecer o processo de ancoragem dos conhecimentos novos sobre os conhecimentos prévios, Silva e Braibante (2018) exemplificam uma situação de aprendizagem na bioquímica orgânica. Para o estudo dos temas carboidratos e proteínas, os conceitos de funções orgânicas (aldeídos, cetonas, aminas, dentre outros) devem estar presentes na estrutura cognitiva do aluno, visto que eles deverão se constituir como os subsunçores que serão responsáveis pela interação com os novos conhecimentos. Todavia, para além dos conhecimentos prévios, a construção da aprendizagem significativa necessita de duas outras condições para a sua obtenção: um material potencialmente significativo e predisposição para aprender pelo estudante (SILVA; BRAIBANTE, 2018).

Cosenza e Guerra (2011, p. 48), quanto à aprendizagem, complementam que o cérebro “está permanentemente preparado para aprender os estímulos significantes e aprender as lições que daí possam decorrer". De acordo com os autores, para os professores tal fato representa:

[...] uma boa notícia para os professores, ao mesmo tempo que é, talvez, o maior desafio que tem no ambiente escolar. Podemos dizer que o cérebro tem uma motivação intrínseca para aprender, mas só está disposto a fazê-lo para aquilo que reconheça como significante. Portanto, a maneira primordial de capturar a atenção é apresentar o conteúdo a ser estudado de maneira que os alunos reconheçam como importante (COSENZA; GUERRA, 2011, p. 48).

O filósofo Sêneca afirmava, há 2000 anos, que se aprendia mais para a escola do que para a vida, uma constatação que, infelizmente, ainda persiste. Os alunos têm como prioridade, 
uma espécie de sobrevivência, aprender para uma aprovação, apesar de que, desta forma, normalmente, os assuntos estudados acabam sendo esquecidos (COSENZA; GUERRA, 2011).

Terá mais chance de ser significante aquilo que tenha ligações com o que já é conhecido, que atenda a expectativas ou que seja estimulante e agradável. Uma exposição prévia do assunto a ser aprendido, que faça ligações do seu conteúdo com o cotidiano do aprendiz e que crie as expectativas adequadas é uma boa forma de atingir esse objetivo (COSENZA; GUERRA, 2011, p. 48).

Acredita-se que o professor ao adotar um modelo mecânico de aprendizado poderá colocar em risco a aprendizagem dos alunos, pois poucas informações serão retidas e por pouco tempo. Defende-se também que a defasagem de assuntos apresentados por alunos na Educação Básica, especialmente em Ciências e Matemática, tenha uma relação direta com a dificuldade na assimilação dos temas estudados, por meio de um ensino que, geralmente, prioriza repetições mecânicas de fórmulas com os estudantes. Ausubel (2000) alerta também com relação à capacidade de relação arbitrária e literal para com a estrutura cognitiva, pois:

[...] torna as tarefas de aprendizagem por memorização altamente vulneráveis à interferência de materiais semelhantes, anteriormente aprendidos e descobertos de forma simultânea ou retroactiva. [...] é este tipo de capacidade de relação basicamente diferente para com a estrutura cognitiva (arbitrária e literal versus não arbitrária e não literal) que justifica a diferença fundamental entre os processos de aprendizagem por memorização e significativa (AUSUBEL, 2000, p. 4).

Na obra de David Ausubel, ele relata, por diversas vezes, que a diferença principal entre a aprendizagem por recepção e a aprendizagem por descoberta reside no fato de como o que deverá ser aprendido é apresentado aos aprendizes. Se o objeto de estudo for apresentado somente na forma substantiva, em que o estudante precisará apenas lembrar, superficialmente, do que foi estudado, assim, o professor terá realizado uma aprendizagem por recepção.

Por outro lado, se o conteúdo for apresentado ao estudante contando com situaçõesproblema, devendo o aluno indicar proposições e buscar soluções, através de investigação e discussão com o professor e demais colegas, desse modo, a abordagem apresentará características de uma aprendizagem por descoberta e, consequentemente, na visão de Ausubel, o objeto de estudo será assimilado mais facilmente.

[...] a diferença principal entre aprendizagem proposicional tal como encontrada nas situações de aprendizagem por recepção, por um lado, e nas aprendizagens por descoberta, por outro lado, reside no facto de o conteúdo principal daquilo que deve ser apreendido ser descoberto ou, pelo contrário apresentado ao aprendiz. Na aprendizagem por recepção, este conteúdo é apresentado sob a forma de uma proposição substantiva ou que não apresenta problemas, que o aprendiz apenas necessita de compreender e lembrar. Por outro lado, na aprendizagem por descoberta, o aprendiz deve em primeiro lugar descobrir este conteúdo, criando proposições que representem soluções para os problemas suscitados, ou passos sucessivos para a resolução dos mesmos (AUSUBEL, 2000, p. 5). 
No que se refere aos estudos que envolvem Neurociência e ensino de Ciências e Matemática, pode-se destacar as pesquisas de Kevin Dunbar, possivelmente o primeiro a dar passos a fim de integrar essas áreas, procurando entender como os alunos assimilam conceitos físicos e astronômicos, e como se dá o processo de mudança conceitual (BROCKINGTON, 2011).

Brockington (2011) revela que Kevin Dunbar investigou como estudantes de graduação explicam as diferenças nas estações do ano. Inicialmente, os dados obtidos revelaram que $94 \%$ dos alunos apresentam concepções alternativas sobre este assunto, por exemplo, a maioria respondeu que o fenômeno se deve a variações da distância entre a Terra e o Sol.

Damasceno Júnior e Romeu (2018, p. 233), argumentam que "as concepções alternativas são concebidas como obstáculos epistemológicos que comprometem uma aprendizagem científica, como, por exemplo, a assimilação de conceitos astronômicos". Plummer (2006) pressupõe que concepções alternativas em crianças e adolescentes incorrem devido a estes não receberem corretas instruções de seus pais e de outros adultos que interagem. A autora expõe que crianças e adultos não têm o hábito de realizar observações do movimento de corpos celestes.

Ainda sobre o experimento realizado por Dunbar, após sua $1^{\mathrm{a}}$ fase, apresentou-se aos alunos um vídeo da NASA (Agência Espacial Norte Americana) explicando que, na verdade, as estações do ano resultam da inclinação da Terra em relação ao plano de sua órbita. Apesar disso, mesmo com a oportunidade para corrigir a explicação inicial, somente um estudante conseguiu alterar corretamente as respostas (BROCKINGTON, 2011).

[...] os estudantes se depararam com as informações que são consistentes com as suas teorias preferenciais, regiões do cérebro que estão associadas à aprendizagem (ou seja, núcleo caudado e o giro para-hipocampal) apresentaram aumento dos níveis de ativação em relação ao valor basal. No entanto, quando os sujeitos foram apresentados a dados que eram incompatíveis com a sua teoria preferida, regiões como o cíngulo anterior, precuneus e córtex pré-frontal dorsolateral mostraram um aumento dos níveis de ativação. O cíngulo anterior é tido como uma região do cérebro associada com a detecção de erro e controle de conflitos enquanto o córtex pré-frontal dorsolateral é considerado uma das regiões principais envolvidas no processamento consciente de informação e memória de trabalho. Estes resultados indicam que quando os dados são consistentes com a teoria, então pequenas mudanças nos conceitos são atingidas através de estruturas padrão de aprendizagem (apud Brockington, 2011, p. 35-36, DUNBAR; FUGELSANG et al., 2007, p. 5).

Quanto à forma que os participantes trataram os dados:

[...] Do ponto de vista da educação científica esses dados mostram claramente que apenas apresentar anomalias aos alunos não irá produzir uma mudança conceitual. $\mathrm{O}$ que os resultados dessas duas experiências mostram é que a crença em uma teoria prévia influencia a interpretação dos dados de uma forma altamente específica. Especificamente, dados inconsistentes com nossas expectativas são tratados como 
erros e, portanto, não são facilmente incorporados na representação de mundo do sujeito (apud BROCKINGTON, 2011, p. 36, DUNBAR; FUGELSANG et al., 2007, p. 5).

Com relação à oferta da disciplina de Neurociência no Brasil para a formação do professor de Ciências e Matemática, como, por exemplo, de Física, Vizzotto (2019) constatou que nenhum dos cursos investigados em sua pesquisa oferta disciplinas obrigatórias. Tal resultado vai ao encontro dos achados nas pesquisas de GROSSI et al. (2014) e Fonseca e Cássia (2012), relacionadas a outras áreas do conhecimento.

Notou-se também nos trabalhos acima mencionados uma pouca adesão à integração entre licenciatura e neurociência, sendo raros os cursos que apresentam disciplinas da área ou de áreas correlatas com a temática no território brasileiro. Uma intrigante questão, pois, segundo Vizzotto (2019, p. 162), apesar da neurociência por si só não resolver todos os problemas, "mas pode ser uma ferramenta de auxílio aos docentes, fornecendo bases para compreender, de maneira abrangente, as idiossincrasias da aprendizagem humana". Em meio a todo esse cenário, Cosenza e Guerra (2011, p. 73) recomendam que:

[...] os conhecimentos da psicologia cognitiva e da neurobiologia não trazem uma receita para a construção de uma estratégia infalível a ser utilizada no ambiente escolar. Contudo, sabemos que as estratégias mais eficientes serão aquelas que atentem para os princípios do funcionamento do cérebro, que devem ser respeitados para uma aprendizagem mais eficiente [...] (COSENZA; GUERRA, 2011, p. 73).

\section{Metodologia}

Este trabalho consiste num levantamento bibliográfico sobre a compreensão do erro à luz da Neurociência, com vistas a contribuir no processo de ensino e aprendizagem de Ciências e Matemática, tomando por base os autores da área, documentos oficiais nacionais e resultados de pesquisas anteriores descritos em artigos, dissertações e teses, no período de 1983 a 2019, incluindo até mesmo um trabalho do corrente ano, por meio de consultas a plataformas digitais. Segundo Gil (2008), uma pesquisa bibliográfica é desenvolvida com base em material já elaborado, constituído principalmente de livros e artigos científicos.

Este trabalho teve uma abordagem qualitativa e de natureza aplicada. Segundo Rossman e Rallis (1998 apud Creswell, 2007, p. 186), na pesquisa qualitativa o investigador pode "desenvolver um nível de detalhes sobre a pessoa ou sobre o local e estar [...] envolvido nas experiências reais dos participantes". A pesquisa se classifica como aplicada em razão de ter sido voltada para a elaboração de diagnósticos, identificação de problemas e busca de soluções. De acordo com Thiollent (2009, p. 36), este tipo de pesquisa responde às necessidades levantadas por "clientes, atores sociais ou instituições". 
As consultas foram realizadas através da busca pelos termos-chaves "Erro no processo de ensino e aprendizagem", "Aprendizagem Significativa", "Neurociência", "Neurociência e ensino de Física e Astronomia" e "Concepções Alternativas no ensino de Física e Astronomia”, em plataformas, a saber: Periódicos da Capes, que engloba as principais bases de dados (Biblioteca Digital de Teses e Dissertações (BDTD), Scientific Electronic Library Online (SciELO), Google Acadêmico, entre outras. É importante destacar que alguns desses textos foram utilizados como consulta ou fundamentação de partes do artigo. Analisou-se a qualidade das produções científicas através da pertinência dos resumos dos trabalhos em relação ao objeto de estudo desta pesquisa. Avaliou-se também o Qualis dos periódicos das revistas, pelos quais estavam inseridos os artigos.

\section{Resultados}

Desde eras mais remotas até os dias atuais são atribuídas no processo de aprendizagem diferentes conotações para o erro. Sabe-se que algumas conotações são de caráter bastante pejorativo, ora no meio acadêmico, ora no contexto escolar. Apesar de que, através da análise dos erros, podemos aprender muito com as respostas dadas pelos alunos (CURY, 2007). Além disso, defende-se que respostas diferentes obtidas em desafios iguais resultam de estratégias de comportamento, pois fazem parte do processo de aprendizagem (MENDONÇA et al., 2020).

Desde a Roma Antiga que já se dizia: Errare humano est (Errar é humano). Essa frase recaiu frequentemente no nosso cotidiano como algo aversivo, dotado em seu bojo como "um obstáculo a se superar". Na escola e, mais especificamente, na sala de aula de matemática, errar é terminantemente proibido, pois endossa o pressuposto do discurso de que "um sinal na matemática faz toda a diferença". O erro é ainda visto como uma anomalia a ser vencida (SILVA, 2019, p. 82).

Mendonça et al. (2020) verificaram que em uma amostra de ratos, face a um mesmo desafio, alguns apresentavam respostas mais rápidas, enquanto outros respostas mais lentas, semelhante ao que vemos com humanos em algumas situações diárias. Contrário a algumas interpretações que acreditam que as respostas corretas ou erradas se devem a um "ruído" neural, os investigadores dessa relevante pesquisa no campo da Neurociência explicaram que essa variabilidade, de fato, deve-se ao reflexo de uma estratégia comportamental (MENDONÇA et al., 2020).

Os autores inferiram também que, a cada novo julgamento, os ratos reajustavam o seu comportamento de acordo com os resultados do julgamento anterior. Para eles, essa é uma relevante estratégia, visto que o ambiente muda constantemente, em decorrência disso, os 
animais precisam se ajustar ao novo, construir uma nova tomada de decisão (MENDONÇA et al., 2020).

Mendonça et al. (2020) explicitaram que mesmo os ratos estando dentro de caixas, ou seja, num ambiente desconhecido, diferente do seu mundo natural, não cessaram o ímpeto de aprender, eles buscam sempre aprender. Então, conforme o mencionado, os ratos apresentam, da mesma forma que os humanos, características de avaliar suas decisões e, dessa forma, alterar o seu comportamento (MENDONÇA et al., 2020). Em vista disso, das relevantes contribuições da Neurociência no processo de aprendizagem, Silva (2019, p. 23) orienta que:

\begin{abstract}
Ao entrar em contato com aportes teóricos oriundos da Neurociência Cognitiva, o professor-pesquisador pode conhecer a perspectiva da aprendizagem no cérebro humano. A neuroeducação, área recente do conhecimento que abarca os conhecimentos do cérebro e os processos de aprendizagem, amalgamou ainda mais os anseios sobre a investigação inicial (SILVA, 2019, p. 23).
\end{abstract}

Levando-se em consideração que uma tomada de decisão equivocada pode resultar num erro, a fim de atenuar as dificuldades na aprendizagem de Matemática, como, por exemplo, em trigonometria, Silva (2019, p. 67) propõe que esta componente curricular "precisa de fato ser analisada em relação aos obstáculos causados pelos erros, dentro da transposição didática que o professor faz para ensinar e em pensar em sua estratégia em um sistema de ensino, ou didática". Os erros são, dessa forma, uma parte dessa relação ou se transfiguram em obstáculos que impedem a relação adequada (SILVA, 2019, p. 68).

\footnotetext{
Desse modo, o obstáculo epistemológico não deve ser encarado como um percalço e sim como uma fase na construção do conhecimento, pois este não é um fim em si mesmo. Esse primeiro esboço de como a trigonometria avançou dentro das perspectivas histórica e epistemológica e como seus obstáculos contribuíram para fazer dela o que ela é hoje e o prelúdio da importância do erro no pressuposto pedagógico (SILVA, 2019, p. 53).
}

D’Amore (2005) revela que o "conhecimento" antigo está associado a uma ideia que teve êxito na resolução de um problema anterior, havendo uma tendência em conservá-la, apesar desta se mostrar ineficiente na resolução de um novo problema. Corroborando com D’Amore (2005), Silva (2019) aponta que o aluno procura repetir a mesma estratégia de resolução do exercício anterior; não obtendo sucesso, distorce os caminhos da resolução a partir dessa percepção inadequada (SILVA, 2019). Em vista disso, Almouloud (2007, p. 130) direciona que:

[..] a maioria dos pesquisadores em didática da matemática defende a ideia de que um dos fatores que mais influenciam essa aprendizagem é o tratamento que o professor dá ao erro do aluno. Tal tratamento está intimamente ligado à concepção de aprendizagem que esse professor tem (ALMOULOUD, 2007, p. 130). 
Mediante o exposto, Silva (2019, p. 86) dimensiona a importância do erro no processo de aprendizagem:

O direito ao erro é necessário para se entender o processo do conhecimento, entendendo esse erro como um saber em gênese, portanto se faz necessário uma análise didática que proporcione ao pesquisador e ao professor um crivo sobre essas condições do erro na construção e constituição do conhecimento matemático, bem como sobre a sua aprendizagem (SILVA, 2019, p. 86).

Nesse aspecto, Silva (2019, p. 117) conclui que:

\begin{abstract}
No ensino, essas assertivas não podem ficar omissas. O professor deve recorrer sempre que possível à história, pois ao saber as dificuldades e obstáculos epistemológicos pode entender como seu aluno também pode se comportar diante das peculiaridades, nem sempre tácitas, do conhecimento em questão. $O$ erro não pode ser quitado do processo de construção didática e epistemológica. A transposição didática em jogo, com suas nuances e seus desafios são gerados pelas implicações anteriores de como, epistemologicamente e historicamente, a trigonometria foi construída e qual o efeito disso nessa transposição (SILVA, 2019, p. 117).
\end{abstract}

Rozal et al. (2017) explicitam que na sala de aula, geralmente, o professor acredita que o estudante não sabe um conteúdo, na verdade a sua falta de compreensão se deve ao fato de que outro conteúdo não foi bem compreendido em outra ocasião e/ou tempo de aprendizagem. Isto revela a diferença entre tempo de ensino (momento em que o conteúdo é ensinado) e tempo de aprendizagem (tempo em que o aluno compreenda e assimile o que foi ensinado). Acreditase que a referida situação pode ser uma das causas que levam o aluno ao erro, em razão da necessidade de o indivíduo requerer um tempo adequado ao seu ritmo de aprendizagem. Diante disso, o professor precisa sempre considerar esse aspecto, que poderá ser um fator potencializador ou limitante na assimilação dos conceitos pelo aluno.

Face às possibilidades da Neurociência no processo de aprendizagem, Vizzotto (2019, p. 54) discorre que:

[...] é relevante refletir sobre o papel da neurociência para a compreensão da aprendizagem. Pela primeira vez, esse campo de estudo tem a oportunidade de observar, por meio de observações diretas, o funcionamento cerebral, as sinapses e como as várias regiões do cérebro podem atuar durante o processo de interação com os conhecimentos (VIZZOTTO, 2019, p. 54).

Apesar das potencialidades da Neurociência, ela representa um campo ainda em ascensão no contexto educacional. Apresenta-se como uma área do conhecimento com possibilidade de contribuir, significativamente, na compreensão do processo de ensino e aprendizagem (VIZZOTTO, 2019).

Atualmente, boa parte dos professores de Física e de outras componentes curriculares da Área de Ciências da natureza defende a aprendizagem por descoberta, entretanto, somente o 
fato do conteúdo principal ser descoberto pelo aluno não será suficiente para uma aprendizagem significativa. Sobre tarefas propostas em aprendizagem por memorização, Ausubel (2000, p. 4) esclarece que:

[...] não se levam a cabo num vácuo cognitivo. Podem relacionar-se com a estrutura cognitiva, mas apenas de uma forma arbitrária e literal que não resulta na aquisição de novos significados. Visto que por exemplo, os membros de estímulo e de resposta específicos de um determinado par de adjectivos, numa aprendizagem de associação de pares, estão ligados de uma forma puramente arbitrária, não existe base possível para de modo não arbitrário a tarefa de aprendizagem à estrutura cognitiva de alguém e o aprendiz deve também lembrar-se literalmente da resposta para cada palavra de estímulo (não pode utilizar sinónimos) (AUSUBEL, 2000, p. 4).

A aprendizagem por memorização ainda é muito presente nas escolas brasileiras, como informam inúmeros investigadores. Lamentavelmente, ela ocorre de forma simplesmente arbitrária, não proporcionando a aquisição de novos conceitos, sendo o indivíduo dependente da associação entre estímulo e resposta. Basta apenas ao indivíduo ser dado um estímulo diferente, até mesmo um sinônimo, dificilmente ele apresentará corretamente a resposta.

A aprendizagem significativa para os estudantes deve ser priorizada pelos professores no processo de ensino e aprendizagem, considerando que ela simboliza uma relevante alternativa com vistas a romper com metodologias tradicionais, em razão da necessidade de metodologias construtivistas, com o propósito de que o conhecimento sofra uma transformação, deixe a condição de mecânico e passe a ter um sentido para o estudante (SILVA; BRABANTE, 2018).

Uma informação somente se fixará no cérebro, com registro ou traço permanente, através de um trabalho adicional. Os estudos da psicologia cognitiva revelam que, nesta fase, são imprescindíveis os processos de repetição, elaboração e consolidação (COSENZA; GUERRA, 2011).

[...] observamos a repetição do uso da informação, juntamente com sua elaboração, ou seja, sua associação com os registros já existente, o que fortalece o traço de memória e o torna mais durável. Quantas vezes mais se repetir essa atividade, o quanto mais ligações, ou "ganchos" forem estabelecidos com informações disponíveis no cérebro, melhor será, pois o registro vai se fixar de forma mais permanente (COSENZA; GUERRA, 2011, p. 62).

Cosenza e Guerra (2011) explicam também que a elaboração pode ser feita de forma simples e até mesmo complexa. Sendo possível envolver diferentes níveis de processamento. Vale frisar que o registro se tornará mais eficiente ao se estabelecer fortemente vínculos e associações entre o novo conteúdo com o já pré-existente em nossa estrutura cognitiva. As “informações aprendidas utilizando o nível mais complexo de elaboração têm mais chance de 
se tornarem um registro forte, uma vez que mais redes neurais estarão envolvidas" (COSENZA; GUERRA, 2011, p. 62).

[...] é importante e útil aproveitar, sempre que possível, mais de um canal sensorial de acesso ao cérebro. Além do processamento verbal, usar os processamentos auditivos, tátil, visual, ou mesmo olfato e a gustação. Além do texto, é bom fazer uso de figuras, imagens de vídeo, música, práticas que envolvam o corpo, etc. (COSENZA; GUERRA, 2011, p. 62-63).

Nesse viés, um ensino significativo provoca alterações na taxa de conexão sináptica e afeta a função cerebral. Desse modo, é possível estabelecer um interessante paralelo entre a psicologia cognitiva com a teoria de Ausubel, devido a interações que ocorrem durante o processo de aprendizagem. É possível inferir que, partindo das premissas das teorias, ideias e discussões supracitadas, por meio da interlocução entre a Neurociência e a Aprendizagem Significativa, o aluno assimilará mais eficientemente os conteúdos de Ciências e Matemática se o professor estabelecer diferentes conexões entre os novos conceitos a serem estudados e os já existentes na estrutura cognitiva do indivíduo, sem esquecer que os instrumentos/estímulos precisam ser instigantes/significativos para o aprendiz. Vizzotto $(2019$, p. 157) revela sobre a Neurociência que:

[...] possui ferramentas que possibilitam conectar as medidas indiretas realizadas por autores clássicos da psicologia da aprendizagem com o funcionamento real de um cérebro. São numerosas as frentes potenciais para temáticas de estudo dentro do ensino e aprendizagem e poderão contribuir de maneira substancial dentro de pesquisas semelhantes a essa, que se dedicam inferir aspectos da retenção e manuseio de saberes (VIZZOTTO, 2019, p. 157).

Por meio das "âncoras", do processo de ancoragem, é possível estabelecer uma interconexão entre a teoria da Aprendizagem Significativa com os conceitos básicos da Neurociência na Educação (ROZAL et al., 2017). Por exemplo, a Programação Neurolinguística faz uso da "ancoragem" para inserir os aprendentes dentro de um nível mental. Nesse contexto, outro exemplo, um indivíduo ao ouvir uma canção favorita antiga, todas as sensações daquela época retornam à sua memória, em decorrência disso, e as velhas vozes as imagens daqueles lugares preferidos podem ressurgir (MUNIZ, 2014).

Todavia, apesar de se observar certa euforia em relação às contribuições das neurociências para a educação, Vizzotto (2019) adverte que elas não propõem uma nova pedagogia, muito menos prometem soluções definitivas para as dificuldades da aprendizagem. Em linhas gerais, as neurociências podem colaborar para a reelaboração/ressignificação de práticas pedagógicas que já acontecem nas escolas e propor intervenções, reiterando que as 
estratégias pedagógicas que respeitam o funcionamento do cérebro, possivelmente, serão mais eficientes (VIZZOTTO, 2019).

Os avanços das neurociências permitem uma abordagem mais científica do processo ensino-aprendizagem a partir da compreensão dos processos cognitivos mobilizados. Porém, é preciso cautela, apesar de todo otimismo em relação às contribuições decorrentes da interlocução entre neurociências e educação (VIZZOTO, 2019). Corroborando com Vizzoto (2019), Cosenza e Guerra (2011, p. 143) concebem que:

O trabalho do educador pode ser mais significativo e eficiente quando ele conhece o funcionamento cerebral. Conhecer a organização e as funções do cérebro, os períodos receptivos, os mecanismos da linguagem, da atenção e da memória, as relações entre cognição, emoção, motivação e desempenho, as dificuldades de aprendizagem e as intervenções a elas relacionadas contribui para o cotidiano do educador na escola, junto ao aprendiz e à sua família (COSENZA; GUERRA, 2011, p. 143).

Em resumo, Cosenza e Guerra (2011, p. 143) revelam que no Brasil:

[...] a maior parte dos educadores que trabalham na administração pública e também na frente de batalha, ou seja, nas escolas, tem uma formação fundamentalmente humanística, essencial para a compreensão da educação, mas insuficiente para o atendimento das demandas da aprendizagem para a vida em sociedade neste milênio. Ao conhecer o funcionamento do sistema nervoso, os profissionais da educação podem desenvolver melhor seu trabalho, fundamentar e melhorar sua prática diária, com reflexos no desempenho e na evolução dos alunos. Podem interferir de maneira mais efetiva nos processos do ensinar e aprender, sabendo que esse conhecimento precisa ser criticamente avaliado antes de ser aplicado de forma eficiente no cotidiano escolar. Os conhecimentos agregados pelas neurociências podem contribuir para um avanço na educação, em busca de melhor qualidade e resultados mais eficientes para a qualidade de vida do indivíduo e da sociedade (COSENZA; GUERRA, 2011, p. 143).

Ao versar sobre os conceitos da Neurociência o "cérebro" se torna objeto de estudo, posto isto, para que a aprendizagem em matemática e ciências ocorra é imprescindível que o aluno esteja bem mentalmente, em razão de ser o cérebro o encarregado por fazer o aluno pensar, raciocinar, relacionar ideias e conceitos com o propósito de resolver uma situaçãoproblema. Sendo assim, é no cérebro que se inicia o processo de aprendizagem (ROSAL et al., 2017).

\section{CONSIDERAÇões FinAIS}

Este trabalho realizou um estudo preliminar sobre as contribuições da Neurociência para a compreensão do erro no processo de ensino e aprendizagem em Ciências e Matemática. Uma discussão teórica visando evidenciar as potencialidades e limitações do papel do erro à luz dos conhecimentos neurocientíficos. Ademais, acredita-se que esta pesquisa será fonte de discussões para o desenvolvimento de futuras investigações nesta área do conhecimento. 
Considerando-se que o cérebro é o órgão responsável pela aprendizagem. Conforme alguns estudos, a aprendizagem foi diretamente responsável pela evolução da humanidade. A atenção e memória possibilitaram que nossa espécie transformasse seus erros em acertos, para a sua própria sobrevivência. O ensino de Ciências e Matemática deve, dessa forma, considerar os conhecimentos da neurociência cognitiva nos seus estudos. Ao mesmo tempo, mobilizar esforços para que ocorram articulações entre campos cognoscíveis, algumas vezes antagônicos, para auxiliarem numa investigação de um problema específico, assim, promover rupturas que serão responsáveis pelo desenvolvimento cognitivo da espécie humana, a exemplo de tantas outras que promoveram importantes avanços sociais, econômicos e científicos.

Este trabalho possibilitou a compreensão que entender a aprendizagem é entender o erro, sua gênese e seu desenvolvimento. Pois, somente assim, será possível superá-lo. Infere-se, neste estudo, que a compreensão dos aspectos neurocientíficos proporcionará uma melhor formação e atuação pedagógica, consequentemente, teremos um profissional que aborde o estudo de Ciências e Matemática com estratégias mais adequadas, que promovam melhores resultados na aprendizagem do aluno.

Com base nos trabalhos analisados, percebeu-se o grande desafio em integrar os conhecimentos da neurociência aos da educação. Entende-se que a aproximação entre essas áreas deve ocorrer com cautela, com intuito de um crescimento mútuo, evitando uma apropriação simplista e prescritiva de conceitos neurobiológicos. Por fim, para além do conhecimento dos mecanismos cerebrais para uma aplicação na educação, a interlocução entre a Neurociência e ensino de Ciências e Matemática deve levar em consideração o papel do erro no processo de aprendizagem, o contexto do sistema educacional, a necessidade de uma adequada fundamentação teórica e metodológica, com o intuito de que interpretações precipitadas, superficiais e equivocadas sejam evitadas.

\section{REFERÊNCIAS}

ALMOUlOUD, Saddo Ag. Fundamentos da Didática da Matemática / Saddo Ag Almouloud. Curitiba: Ed. UFPR, 2007.

ALMOULOUD, Saddo Ag. Fundamentos da Didática da Matemática. $1^{\text {a }}$ ed. Curitiba. PR: Editora UFPR, 2010.

ASTOLFI, Jean Pierre; DEVELAY, Michel. A didática das ciências. Campinas: Papirus, 2002.

AUSUBEL, David Pearl (2000). The acquisition and retention of knowledge: a cognitive view. Dordrecht, Kluwer Academic Pubishers. 210 p. 
BARTOSZECK, Amauri Betini. Neurociência na educação. Revista Eletrônica Faculdades Integradas Espírita, Curitiba, volume 01, p. 1-6, 2006.

BATISTA, Érika da Costa. Neuroeducação e ensino das ciências: contribuições cognitivas para o ensino fundamental I. 2018. 88f. Manaus: Dissertação de Mestrado. Programa de PósGraduação em Educação e Ensino de Ciências na Amazônia - Universidade do Estado do Amazonas, Manaus, 2018. Disponível em: http://177.66.14.82/handle/riuea/2225. Acesso em: 09 jun. 2018.

BRASIL, Ministério da Educação. Secretaria de Ensino Básico. Parâmetros Curriculares Nacionais Ensino Médio. Brasília. MEC/SEB, 2000109 p.

BRASIL, Ministério da Educação, Secretaria de Educação Básica. PCN+: Ensino Médio orientações educacionais complementares aos parâmetros curriculares nacionais. Brasília. MEC/SEB, 2002.

BROCKINGTON, Guilherme. Neurociência e educação: investigando o papel da emoção na aquisição e uso do conhecimento científico. Tese de Doutorado. Programa de Pós-Graduação em Educação. Faculdade de Educação, Universidade de São Paulo, São Paulo, 199 pp. 2011.

BROUSSEAU, Guy. Les obstacles épistemoloques et les problémesem mathématiques. Recherches emDidaticque des Mathématiques. Grenoble : La Pensée Sauvage, v. 4.2 p.164-198, 1983.

CHIQUETTO, Marcos José. O currículo de Física do ensino médio no Brasil: discussão retrospectiva. Revista e-curriculum, São Paulo, v.7 n.1 Abril/2011. Disponível em: http://revistas.pucsp.br/index.php/curriculum. Acesso em: 09 jun. 2020.

COSENZA, Ramon Moreira; GUERRA, Leonor Bezerra. Neurociência e educação: como o cérebro aprende. Porto Alegre: Artmed, 2011.

CRESWELL, John. W. Projeto de pesquisa: métodos qualitativo, quantitativo e misto. 2. ed. Porto Alegre: Artmed, 2007.

CURY, Helena Noronha. Análises de erros: o que podemos aprender com as respostas dos alunos. Belo Horizonte: Autêntica, 2007.

DAMASCENO, Julio Cesar Gonçalves. O ensino de astronomia como facilitador nos processos de ensino e aprendizado. Dissertação de Mestrado. Programa de Pós-Graduação Mestrado Nacional Profissional de Ensino de Física (MNPEF). Universidade Federal do Rio Grande, Rio Grande, 137 pp. 2016.

DAMASCENO JÚNIOR, José Ademir; ROMEU, Mairton Cavalcante. O Planetário como recurso metodológico para facilitar o ensino de Física por meio da ruptura entre o conhecimento científico e o conhecimento comum. Revista Prática Docente, Confresa, v. 3, n. 1, p. 231-248, 2018. Disponível em:

http://periodicos.cfs.ifmt.edu.br/periodicos/index.php/rpd/article/view/206/64. Acesso em: 01 fev. 2020. 
D’AMORE, Bruno. Epistemologia e Didática da Matemática. Trad. Maria Cristina Bonomi Barufi. São Paulo: Escrituras Editora, 2005.

DARROZ, Luiz Marcelo; SANTOS, Flávia Maria Teixeira dos. Astronomia: uma proposta para promover a aprendizagem significativa de conceitos básicos de Astronomia na formação de professores em nível médio. Caderno Brasileiro de Ensino de Física, v. 30, n.1, p. 104$130,2011$.

DUNBAR, Kevin; FUGELSANG, Jonathan et al. Do naive theories ever go away? Using brain and behavior to understand changes in concepts. Thinking With Data, p. 193. 2007.

GIL, Antônio Carlos. Como elaborar projetos de pesquisa. 4 ed. São Paulo: Atlas, 2008.

GROSSI, Márcia Gorett Ribeiro; LOPES, Aline Moraes; COUTO, Pablo Alves. A neurociência na formação de professores: um estudo da realidade brasileira. Revista da FAEEBA-Educação e Contemporaneidade, Salvador, volume 23, n. 41, p. 27-40, 2014.

JARDIM, Luciana de Moraes; CAMARGO, Sergio; ZIMER, Tania Teresinha Bruns. Transposição didática no Ensino de Ciências: Diferentes olhares. In: XII Congresso Nacional de Educação (EDUCERE) 2015. Disponível em:

https://educere.bruc.com.br/arquivo/pdf2015/17323_10412.pdf. Acesso em: 09 jun. 2020.

MENDONÇA, André G. et al. The impact of learning on perceptual decisions and its implication for speed-accuracy tradeoffs. Nat Commun 11, 2757 (2020).

https://doi.org/10.1038/s41467-020-16196-7

MOREIRA, Marco Antonio; MASINI, Salzano Elcie F. et al. Aprendizagem Significativa Condições para ocorrências e lacunas que levam a comprometimentos. 1 ed. São Paulo: Psicopedagógica LTDA, 2008.

MUNIZ, Iana. Neurociência e os exercícios mentais: estimulando a inteligência criativa. Rio de Janeiro: Wak Editora, 2014.

OLIVEIRA, Joselba Liliane; ARRUDA, Aline Mendes de; SILVA, Fernando Carneiro da; CAMARGO, Joseli Almeida (2012). Os Conceitos de erro, obstáculo e contrato didático segundo Guy Brousseau, III EIEMAT Escola de Inverno de Educação Matemática.

PLUMMER, Julia Diane.Students' development of astronomy concepts across time. Doctoral Dissertation, The University of Michigan. 2006.

RELVAS, Marta Pires. Neurociência e transtornos de aprendizagem: as múltiplas eficiências para uma educação inclusiva. 5ª Edição. Rio de Janeiro: Wak Editora, 2011.

ROZAL, Edilene Farias; SOUZA, Ednilson Sergio Ramalho de; SANTOS, Neuma Teixeira dos. Aprendizagem em matemática, aprendizagem significativa e neurociência na educação dialogando aproximações teóricas. Revista REAMEC, Cuiabá - MT, v. 5, n. 1, p. 143-164, 2017. Disponível em: https://doaj.org/article/40292da042374857b93ffdc59d3df699. Acesso em: 09 ago. 2020.

SILVA, Jennifer Alejandra Suárez; BRAIBANTE, Mara Elisa Fortes. Aprendizagem significativa: concepções na formação inicial de professores de Ciências. Revista Insignare 
Scientia, vol. 1, n. 1, p. 1-22, 2018. Disponível em: https://periodicos.uffs.edu.br/index.php/RIS/article/view/7657/5132. Acesso em: 09 ago. 2020.

SILVA, Luciano Pontes da. Um estudo da atenção seletiva na aprendizagem das funções trigonométricas: etiologias e tipologias de erros na perspectiva da neurociência cognitiva. 2019. 209f. São Cristóvão: Dissertação de Mestrado. Programa de Pós-Graduação em Ensino de Ciências Naturais e Matemática - Universidade Federal de Sergipe, São Cristóvão, 2019. Disponível em: https://ri.ufs.br/bitstream/riufs/11410/2/LUCIANO_PONTES_SILVA.pdf. Acesso em: 09 jun. 2020.

SIQUEIRA, Maxwell; PIETROCOLA, Maurício. A Transposição Didática aplicada a teoria contemporânea: A Física de Partículas elementares no Ensino Médio. In: X Encontro de Pesquisa em Ensino de Física - EPEF, 2006, Londrina. Anais do X Encontro de Pesquisa em Ensino de Física - EPEF. v. 1. p. 1-10. Disponível em:

https://scholar.google.com.br/citations?user=_mS4u30AAAAJ\&hl=pt-BR. Acesso em: 10 mai. 2017.

STERNBERG, Robert. J. Psicologia Cognitiva. São Paulo: CengageLearing, 2010.

THIOLLENT, Michel. (2009). Metodologia de Pesquisa-ação. São Paulo: Saraiva.

VIZZOTTO, Patrick Alves. A Neurociência na formação do professor de Física: Análise curricular das licenciaturas em Física da região Sul do Brasil. Revista Insignare Scientia, volume 02, n. 2, p. 150-165, 2019.

WILLINGHAM, Daniel T. Por que os alunos não gostam da escola? Reposta da ciência cognitiva para tornar a sala de aula atrativa e efetiva. Porto Alegre: Artmed, 2011.

Recebido em: 16 de junho de 2020.

Aprovado em: 17 de agosto de 2020. 